\title{
Clinical Trial Investigator Confidentiality Agreement
}

National Cancer Institute

\section{Source}

National Cancer Institute. Clinical Trial Investigator Confidentiality Agreement. NCI

Thesaurus. Code C115476.

A legally binding document established between the trial sponsor and any/all contracted investigators that contains the provisions governing the nondisclosure requirements of any/all information pertaining to the clinical trial. 